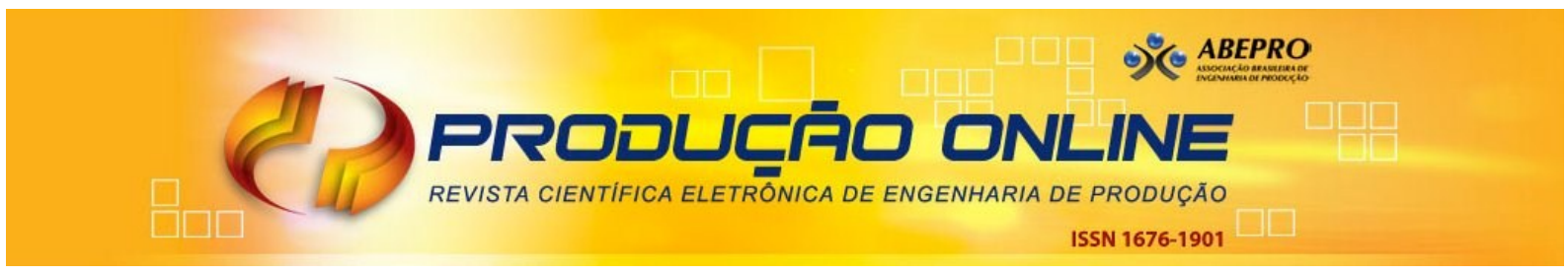

\title{
A ESTRUTURA INTELECTUAL DE INVESTIGAÇÃO DE AGLOMERAÇÕES PRODUTIVAS: UM ESTUDO NO ÂMBITO DA ABEPRO
}

\section{THE INTELLECTUAL STRUCTURE OF RESEARCH IN INDUSTRIAL AGGLOMERATIONS: A STUDY IN THE ABEPRO SCOPE}

\author{
Jaqueline de Fátima Cardoso*E-mail: jaque@ifsc.edu.br \\ Janaína Gularte Cardoso**E-mail: jgcadm@hotmail.com \\ Nelson Casarotto Filho**E-mail: casarotto@deps.ufsc.br \\ *Instituto Federal de Educação, Ciência e Tecnologia de Santa Catarina - IF-SC, Florianópolis, SC \\ ** Universidade Federal de Santa Catarina, UFSC, Florianópolis, SC
}

Resumo: A importância dos estudos em aglomerações produtivas e/ou empresariais é crescente, tendo em vista a relevância que essa estratégia vem ocupando como forma alternativa de competitividade. A partir disso, foram produzidas publicações, pesquisas e conhecimentos sobre diversos aspectos da disciplina. Assim, é interessante avaliar a estrutura intelectual que a comunidade científica atingiu neste âmbito de estudo e os rumos que tomou. Nesta perspectiva, o objetivo da pesquisa foi explorar no âmbito da ABEPRO artigos relacionados ao assunto aglomerações produtivas, no período de 2005 a 2009, detalhando as análises nos anos de 2008 e 2009. Para tal, foi desenvolvido um estudo exploratório, bibliográfico, predominantemente quantitativo com nuances qualitativas nos periódicos da Associação Brasileira de Engenharia de Produção (ABEPRO), nos anais do Encontro Nacional de Engenharia de Produção (ENEGEP) e nos anais do International Conference on Industrial Engineering and Operations Management (ICIEOM). Os principais resultados apontam que a estrutura intelectual de investigação de aglomerações produtivas não oferece referencial teórico e metodológico consolidado. A análise da ABEPRO 2008-2009 fornece evidências para a maturação de novas pesquisas acerca de aglomerações produtivas.

Palavras-chave: Aglomeração produtiva. Arranjo(s) produtivo(s) Local. Rede(s) de Empresas. Cluster(s). ABEPRO.

\begin{abstract}
The importance of studies in productive clusters and / or business is growing view of the importance that this strategy has gained as an alternative form of competitiveness. From this, were produced publications, research and knowledge on various aspects of discipline. Thus, it is interesting to evaluate the intellectual framework that the scientific community has reached this area of study and the direction it took. From this perspective, the research objective was to explore in the articles related to the subject ABEPRO productive agglomerations in the period 2005 to 2009 , detailing the analysis in the years 2008 and 2009. To this end, we developed an exploratory study, literature, predominantly quantitative with qualitative nuances in the journals of the Brazilian Association of Production Engineering (ABEPRO), in the annals of the National Meeting of Industrial Engineering (ENEGEP) and in the annals of International Conference on Industrial Engineering and Operations Management(ICIEOM). The main findings indicate that the intellectual structure of research productive agglomerations not offer theoretical and methodological consolidated. The analysis of ABEPRO 20082009 provides evidence for the maturation of new research on productive agglomerations.
\end{abstract}

Keywords: Agglomeration productive. Local Productive Systems. Companies Network. Clusters. ABEPRO. 


\section{INTRODUÇÃO}

A nova economia estabeleceu uma lógica diferenciada de competição, nem sempre fácil de ser assimilada pelas empresas, especialmente as micro e pequenas.

Sob esse enfoque, o tema aglomeração produtiva tem ganhado relevância significativa nos últimos anos, sobretudo em função dos benefícios obtidos pelas empresas que utilizam essa tipologia estratégica.

O reconhecimento da capacidade competitiva de agrupamentos de empresas passou a ser considerado realidade a partir da década de 1990. Desde então, governos, investidores, políticos e pesquisadores passaram a se interessar por essa área. (ZACCARELLI et al., 2008).

A partir disso, foram produzidas publicações, pesquisas e conhecimentos sobre diversos aspectos das aglomerações produtivas, impulsionados pela relevância que essa estratégia vem ocupando para o desenvolvimento, econômico e social, de localidades e regiões.

Assim, este trabalho tem por objetivo explorar no âmbito da ABEPRO, artigos relacionados ao assunto aglomerações produtivas, fazendo análises da evolução quantitativa e de aspectos qualitativos no período de 2005 a 2009, detalhando as análises nos anos de 2008 e 2009.

O artigo inicialmente apresenta uma breve revisão bibliográfica sobre a temática aglomerações produtivas, destacando os conceitos de arranjo(s) produtivo(s) local(ais) - (APL), rede(s) de empresas e cluster(s). Em seguida, são apresentados os procedimentos metodológicos empregados e os resultados e discussões acerca do levantamento nos periódicos da Associação Brasileira de Engenharia de Produção (ABEPRO), nos anais do Encontro Nacional de Engenharia de Produção (ENEGEP) e nos anais do International Conference on Industrial Engineering and Operations Management (ICIEOM). Por último, são relatadas as considerações finais. 


\section{FUNDAMENTAÇÃO TEÓRICA}

Segundo McCann e Folta (2008), as inferências e o reconhecimento de que as organizações tendem a se aglomerar geograficamente não é novo na literatura. Esse assunto já é abordado por autores clássicos desde o final do século XVII, como por exemplo, a obra de Adam Smith em 1776, que reconhece a importância dos benefícios da divisão do trabalho no crescimento das cidades e, ainda, a obra de Marshall "Principles of Economics" em 1890, onde um dos capítulos se tornou referência na análise das vantagens da aglomeração.

Mais tarde, com os trabalhos de Paul Krugman (1998) e Porter (1998) a temática da aglomeração é resgatada no debate acadêmico e ganha espaço (LEON e MEIRELLES, 2010).

A importância e o interesse no estudo das aglomerações são advindos do fato das vantagens competitivas geradas para as empresas nelas localizadas e pela relevância que essa estratégia vem ocupando para o desenvolvimento de localidades e regiões.

Além disso, o estudo deste tema apresenta várias denominações, tais como: clusters (PORTER, 1999); sistemas locais de produção, arranjos e sistemas produtivos locais (CASSIOLATO e LASTRES, 2002); redes de cooperação, redes de pequenas e médias empresas, consórcios de empresas (CASAROTTO FILHO e PIRES, 2001); aglomerações e sistemas produtivos e inovativos locais (CASSIOLATO e SZAPIRO, 2002); redes de negócios (ZACARELLI et al 2008); entre outros.

Em linhas gerais, estes termos são utilizados para definir um conjunto de empresas que atuam em determinado setor, são interdependentes e possuem relacionamentos com diferentes graus de profundidade. Todavia, muitas vezes é difícil delimitar fronteiras claras entre as diferentes nomenclaturas (clusters, distritos, sistemas, pólos industriais, redes etc).

Dessa forma e para os fins que se destina a presente pesquisa, serão trabalhados os principais pressupostos teóricos referentes aos conceitos arranjo(s) produtivo(s) local(ais) - (APL), rede(s) de empresas e cluster(s). 
O termo Arranjos Produtivos Locais - APL foi concebido no Brasil, junto ao governo federal. Segundo SEBRAE, os Arranjos Produtivos Locais são aglomerações de empresas localizadas em um mesmo território, que apresentam especialização produtiva e mantêm vínculos de articulação, interação, cooperação e aprendizagem entre si e com outros atores locais, tais como: governo, associações empresariais, instituições de crédito, ensino e pesquisa. (TERMO DE REFERÊNCIA PARA ATUAÇÃO DO SISTEMA SEBRAE EM ARRANJOS PRODUTIVOS LOCAIS, 2003).

De acordo com Crocco et al. (2003 apud BARROSO e SOARES, 2009), os arranjos produtivos locais caracterizam-se pela proximidade geográfica, especialização setorial, predominância de pequenas e médias empresas, cooperação e competição interfirmas determinadas pela inovação, troca de informações, organizações de apoio ativas na oferta de serviços e parceria estreita com o setor público local. A inovação destaca-se como fator de competitividade em concentração regional de empresas (BOTELHO e BASTOS, 2011).

Já conforme Albagli e Brito (2003, apud VILPOUX e OLIVEIRA 2010), os arranjos produtivos locais são conjuntos de agentes econômicos, políticos e sociais, articulados em torno de um conjunto específico de atividades econômicas e que apresentam algum tipo de vínculo entre eles. Segundo Ding,(2011), os links entre institutos ou universidades com as empresas são fundamentais para o desenvolvimento de caráter endógeno nos clusters, segundo estudo feito na China.

O termo APL é utilizado no Brasil, no entanto existem outras denominações para esse conceito, como por exemplo, redes de empresa.

Segundo Castells (2000, p. 498), "rede é um conjunto de nós interconectados". O autor ainda acrescenta que redes constituem uma nova lógica de nossa sociedade e isso modifica de forma substancial a operação e os resultados dos processos produtivos.

Para Casarotto Filho e Pires (2001), redes de empresas é um conjunto de empresas interligadas por relacionamentos formais ou negociais, podendo ou não ser circunscrito e uma região.

Em uma conceituação mais geral, Casarotto Filho e Pires (2001) qualificam em micro e macrorrede. A microrrede é uma associação de empresas visando 
garantir competitividade do conjunto. Um consórcio é um exemplo de microrrede. Por outro lado, a macrorrede é a associação, por meio de mecanismos de integração de todas as entidades representativas da região (associações, governos, instituições de pesquisa e suporte, bancos, fórum/agência de desenvolvimento, micro e pequenas empresas, grandes empresas, entre outros.

Zaccarelli et al (2008) afirmam que redes de negócios são arranjos compostos por diferentes negócios que mantêm vínculos e relacionamento em alguma medida entre si. Considerando como elemento-chave desta integração, entre diferentes negócios, os relacionamentos de troca, independente de onde os integrantes da rede estão localizados. No conceito de rede de negócios a idéia de fidelização é de importância central. Entende-se a fidelização como a evolução de uma interação entre negócios, associada ao aprofundamento e a permanência nas transações comerciais entre empresas, uma sendo a vendedora e outra compradora. É possível admitir que exista uma graduação de fidelização com base na intensidade e na natureza das transações.

Já no que se refere a redes de cooperação empresarial, o propósito central, afirmam Balestrin e Verschoore (2008), é reunir atributos que (1) permitam uma adequação ao ambiente competitivo, dentro de uma estrutura dinâmica, com ações uniformizadas, mas descentralizadas; (2) possibilitem ganhos escala com o trabalho conjunto; (3) mas não deixem as empresas envolvidas perderem a flexibilidade.

O termo rede de negócios possui um apelo no sentido de promover o desenvolvimento tanto econômico quanto social. De acordo com Casarotto Filho e Pires (2001), o desenvolvimento regional pode ser a alternativa para o Brasil buscar a superação de problemas como o desemprego. Além disso, o vetor da regionalização social pode atenuar as desigualdades sociais. Para os mesmos autores, o desenvolvimento regional pode ser calcado nos sistemas econômicos locais competitivos. Tais sistemas são o fruto de um planejamento regional que procura ter aglomerações econômicas competitivas, com o adicional do componente social.

Na mesma linha em que a denominação de APL possui convergências com o termo redes de empresas, o termo cluster possui certas semelhanças com os termos anteriores. 
"Clusters são concentrações geográficas de empresas e instituições interconectadas numa área de atuação particular. Eles incluem um conjunto de empresas e outras entidades ligadas que são importantes para a competição" (PORTER, 1998, p. 78). Esse conceito mostra que um cluster inclui um número grande de empresas e instituições que se relacionam no processo de determinação da eficiência de um certo bem ou serviço que ele oferta para os agentes externos à sua cadeia produtiva.

Liao (2008) coloca que a palavra clusters, é interpretada, por parte da maioria dos estudos, como a extensão a que as empresas da mesma ou de indústrias conexas possuem proximidade geográfica entre si.

Acrescenta ainda, que normalmente, os clusters possuem duas características principais: uma é o potencial de fornecer recursos complementares, aprendizagem coletiva e legitimidade; o outro é o seu potencial para intensificar a concorrência e a possibilidade que essa concorrência tem de estimular a competitividade.

Genericamente, os clusters podem ser definidos como uma concentração setorial e espacial de empresas que supõe: a existência de vantagens de aglomeração; a questão da especialização e das trocas; clara especialização produtiva, na qual o comércio entre as empresas participantes é substancial; à intensidade das trocas intra-aglomeração; pela existência de relações de cooperação entre firmas, grau de especialização e desintegração vertical da aglomeração, ambiente institucional voltado para dar suporte ao desenvolvimento do cluster, dentre outros. (CROCCO et al., 2003; PORTER, 1998; LIAO, 2008).

$\mathrm{Na}$ visão Casarotto Filho e Pires (2001), cluster é constituído por uma concentração regional de empresas voltadas ao mesmo segmento produtivo, esta concentração é consolidada havendo forte interação entre as empresas, estendendo verticalmente a jusante e a montante, lateralmente e comporta entidades de suporte privadas e governamentais.

Para Zaccarelli et al (2008), clusters também são caracterizados por diferentes negócios com relacionamentos em diversos níveis de profundidade, no entanto, o elemento chave desta integração é a proximidade geográfica. 
Independentemente da tipologia do cluster e dos elementos que incorpora, a questão essencial e concreta que dá substância ao conceito são os ganhos advindos da proximidade geográfica entre agentes econômicos. Essa é uma observação mais geral que se pode tirar da leitura desses autores sobre o conceito de cluster.

Neste trabalho, as designações clusters, rede de empresas, arranjos produtivos locais, aglomerações industriais ou concentrações de empresas não se referem às tipologias e classificações dadas a elas, mas, sim, caracterizam o mesmo objeto que é a proximidade de empresas especializadas em uma mesma atividade econômica, as quais podem auferir vantagens de aglomeração.

\section{PROCEDIMENTOS METODOLÓGICOS}

A partir das considerações contidas na fundamentação teórica, apresentam-se neste tópico os procedimentos metodológicos que possibilitaram a consecução dos objetivos pré-estabelecidos para o estudo.

No que tange ao delineamento, este estudo se caracterizou quanto ao objetivo como exploratório, quanto ao objeto como bibliográfico e à abordagem foi predominantemente quantitativa com nuances qualitativas.

De acordo com Thiollent (1980, p.48), a pesquisa exploratória "consiste em descobrir o campo de pesquisa (...) e estabelecer um primeiro diagnóstico da situação, dos problemas prioritários (...)."

A pesquisa bibliográfica é aquela que é elaborada a partir de material já publicado (GIL, 1999).

Para Roesch (1996), a pesquisa quantitativa é utilizada quando o propósito do projeto mede relações entre variáveis e avalia as consequências, para garantir uma boa interpretação dos resultados. Assim sendo, a presente pesquisa foi realizada por meio de uma exploração bibliográfica quantitativa nos periódicos da Associação Brasileira de Engenharia de Produção (ABEPRO), nos anais do Encontro Nacional de Engenharia de Produção (ENEGEP) e nos anais do International Conference on Industrial Engineering and Operations Management (ICIEOM). Dessa forma, os dados coletados nesta pesquisa originaram-se de fontes secundárias de dados e 
essas fontes secundárias foram constituídas por artigos publicados nos anos de 2005, 2006, 2007, 2008 e 2009.

O critério de seleção foi o conteúdo dos artigos: em uma primeira amostragem, foram selecionados todos os artigos relacionados ao assunto aglomerações produtivas, utilizando como variável de corte os termos: arranjo(s) produtivo(s) local(ais) - (APL), rede(s) de empresas e cluster(s). Esta etapa resultou em 286 artigos A partir disso, se fez uma análise cruzada (palavras-chave; título e resumo) com os termos citados e as palavras: desenvolvimento local, desenvolvimento regional, crédito, financiamento, governança, aliança, consócio, estratégia. A escolha destas palavras foi motivada por representarem termos utilizados em situações da existência de aglomerações produtivas. Ao término desta etapa foram selecionados 160 artigos. A partir disso, as análises se concentraram, de forma detalhada, nos anos de 2008 e 2009.

Para o processo de análise e interpretação dos dados coletados (títulos, autores, instituição e palavras-chave), foi utilizada a técnica de tabulação por meio eletrônico, via software Excel. Segundo Rauen (2002), essa técnica consiste na contagem dos elementos que se conformam com cada categoria ou classe estabelecida na etapa de classificação.

Cabe acrescentar ainda, que a partir dos dados eletronicamente tabulados foram construídos gráficos, quadros e tabelas, no sentido de sistematizar as informações e organizá-las de modo a atingir os objetivos desse estudo.

Já para a análise dos resumos dos artigos, utilizou-se o método de leitura vertical e horizontal de Thiollent, o qual trouxe as nuances qualitativas para o estudo. Através deste método, inicialmente, fez-se leituras verticais dos conteúdos dos resumos dos artigos, após efetuou-se as leituras horizontais, destacando aspectos essenciais à satisfação do objetivo deste trabalho. (THIOLLENT, 1980)

Em suma as partes analisadas dos artigos foram: título, autores, instituição, palavras-chave e resumo. Por fim, é importante ressaltar que a análise geral incluiu os anos de 2005 a 2009. Já a análise detalhada, por ano, foi realizada para os anos de 2009 e 2008. 


\section{RESULTADOS E DISCUSSÕES}

Para a consecução dos objetivos delineados, a presente pesquisa foi realizada por meio de uma exploração quantitativa nos periódicos da Associação Brasileira de Engenharia de Produção (ABEPRO), nos anais do Encontro Nacional de Engenharia de Produção (ENEGEP) e nos anais do International Conference on Industrial Engineering and Operations Management (ICIEOM).

A escolha da ABEPRO baseou-se na importância e representação desta instituição na área de Engenharia de Produção. Congregando docentes, discentes e profissionais de Engenharia de Produção, a associação atua a mais de 20 anos assumindo funções fundamentais para o desenvolvimento da área no país.

Já a escolha do ENEGEP, dentre os eventos organizados pela ABEPRO, é advinda do fato de tal evento ser de âmbito nacional e objetivar reunir a comunidade acadêmica, pesquisadores, professores, estudantes, empresários, consultores, engenheiros, administradores e demais profissionais atuantes na Engenharia de Produção. O ENEGEP caracteriza-se como um dos principais divulgadores da produção técnica e científica da área e se consolidou como fórum de discussão de questões pertinentes à Engenharia de Produção no âmbito nacional.

Cabe destacar que a exploração quantitativa incluiu os anos de 2005, 2006, 2007, 2008 e 2009 dos periódicos publicados pela Associação Brasileira de Engenharia de Produção que são: The Brazilian Journal of Operations \& Production Management (BJO\&PM), Revista Produção e Revista Produção Online.

Inicialmente, a busca realizada no conteúdo dos artigos teve como critério os temas: arranjo(s) produtivo(s) local(is) (APL), rede(s) de empresas e cluster(s). A partir dessa, obteve-se a distribuição da produção dos artigos. O Quadro 1 mostra a distribuição do número total de artigos por tema, no ENEGEP e nos Periódicos e, o número absoluto dos artigos, nos três temas específicos, por ano de publicação. 
Quadro 1 - Distribuição inicial de artigos por ano e temas.

\begin{tabular}{|c|c|c|c|c|}
\hline ANO & APL & REDE & CLUSTER & TOTAL TEMAS/ANO \\
\hline 2009 & 11 & 2 & 10 & $\mathbf{2 3}$ \\
\hline 2008 & 5 & 4 & 14 & $\mathbf{2 3}$ \\
\hline 2007 & 29 & 8 & 57 & $\mathbf{9 4}$ \\
\hline 2006 & 18 & 10 & 57 & $\mathbf{8 5}$ \\
\hline 2005 & 16 & 8 & 37 & $\mathbf{6 1}$ \\
\hline TOTAL & $\mathbf{7 9}$ & $\mathbf{3 2}$ & $\mathbf{1 7 5}$ & $\mathbf{2 8 6}$ \\
\hline
\end{tabular}

Fonte: Dados primários (2010)

Mediante a análise do quadro supracitado verificou-se que $28 \%$ dos artigos são referentes a arranjos produtivos locais, $11 \%$ a rede de empresas e $61 \%$ cluster. No entanto, observou-se por meio de uma análise dos resumos, que nem todos os artigos relacionados aos temas pesquisados tratam dos conceitos de APL, rede de empresas e cluster aplicados neste trabalho. Uma parcela expressiva dos trabalhos usava cluster como sinônimo de análise de cluster, um procedimento multivariado para detectar grupos homogêneos nos dados.

Sendo assim, restaram 159 artigos que efetivamente tratam dos temas propostos, conforme o Quadro 2.

Quadro 2 - Distribuição dos artigos por fonte e ano.

\begin{tabular}{|c|c|c|c|c|c|}
\hline ANO & ENEGEP & ICIEOM & $\begin{array}{c}\text { REVISTA PRODUÇÃO } \\
\text { ONLINE }\end{array}$ & $\begin{array}{c}\text { REVISTA } \\
\text { PRODUÇÃO }\end{array}$ & $\begin{array}{c}\text { TOTAL POR } \\
\text { ANO }\end{array}$ \\
\hline 2005 & 37 & 0 & 0 & 0 & $\mathbf{3 7}$ \\
\hline 2006 & 38 & 0 & 2 & 2 & $\mathbf{4 2}$ \\
\hline 2007 & 47 & 1 & 2 & 0 & $\mathbf{5 0}$ \\
\hline 2008 & 13 & 1 & 0 & 1 & $\mathbf{1 5}$ \\
\hline 2009 & 14 & 1 & 0 & 0 & $\mathbf{1 5}$ \\
\hline TOTAL & $\mathbf{1 4 9}$ & $\mathbf{3}$ & $\mathbf{4}$ & $\mathbf{3}$ & $\mathbf{1 5 9}$ \\
\hline
\end{tabular}

Fonte: Dados primários (2010)

A partir dos dados do Quadro 2, observou-se que 94\% das publicações referentes aos temas arranjos produtivos locais, rede de empresas e cluster são em congressos. Além disso, $81 \%$ das publicações se concentraram nos anos de 2005 , 2006 e 2007, com destaque para 2007 que obteve 31\% das publicações.

Dessa forma, é importante citar brevemente os temas propostos para os referidos ENEGEP`s, no intuito de avaliar se o tema do congresso impulsionou o número de publicações na área em estudo.

O tema geral proposto para o Enegep 2009 foi "A Engenharia de Produção e o Desenvolvimento Sustentável: Integrando Tecnologia e Gestão". Havia um sub- 
tema relacionado à área denominado Redes de Empresas e Gestão da Cadeia Produtiva.

O evento de 2008, cujo tema geral foi "A Integração de Cadeias Produtivas com a Abordagem da Manufatura Sustentável.

Em 2007, "A energia que move a produção: um diálogo sobre integração, projeto e sustentabilidade" foi o tema central e a subárea Redes de Empresas e Gestão da Cadeia Produtiva foi apresentada.

"Ética e Responsabilidade Social - a contribuição do engenheiro de produção" foi o tema proposto em 2006, ano que não houve subáreas correlacionadas a arranjos, redes ou clusters. Quanto ao ENEGEP de 2005, não se pode verificar menção ao tema central do congresso.

Em 2005 e 2006 não se verificou relação direta do tema do congresso e/ou subáreas com o número de publicações na área. No entanto, em 2007, ano que apresenta o maior número de publicações, foi que uma subárea relacionada a redes e aglomerações foi criada no ENEGEP. Assim, verifica-se que o número de publicações nesse ano foi impulsionado pela criação de uma área específica.

\subsection{Análise do período de 2009}

Em 2009, os temas arranjos produtivos locais, rede de empresas e cluster totalizaram 15 artigos, destes 14 foram publicados no ENEGEP e 1 no ICIEOM.

Além disso, para os 14 artigos identificou-se 50 autores, perfazendo uma média aproximada de 3,57 autores por artigo.

Já no que se refere ao número de instituições obteve-se 17 , número pouco representativo frente ao universo de instituições de ensino superior no Brasil. Dentre essas, as instituições com maior percentual de publicação foram: Universidade de Caxias do Sul, 13\%; Universidade Estadual de Maringá, Universidade Federal de Campina Grande e Universidade de Taubaté, com 10\% cada.

O Gráfico 1 apresenta a distribuição percentual das publicações por instituição de ensino. 
Gráfico 1- Distribuição percentual das publicações por instituição de ensino 2009.

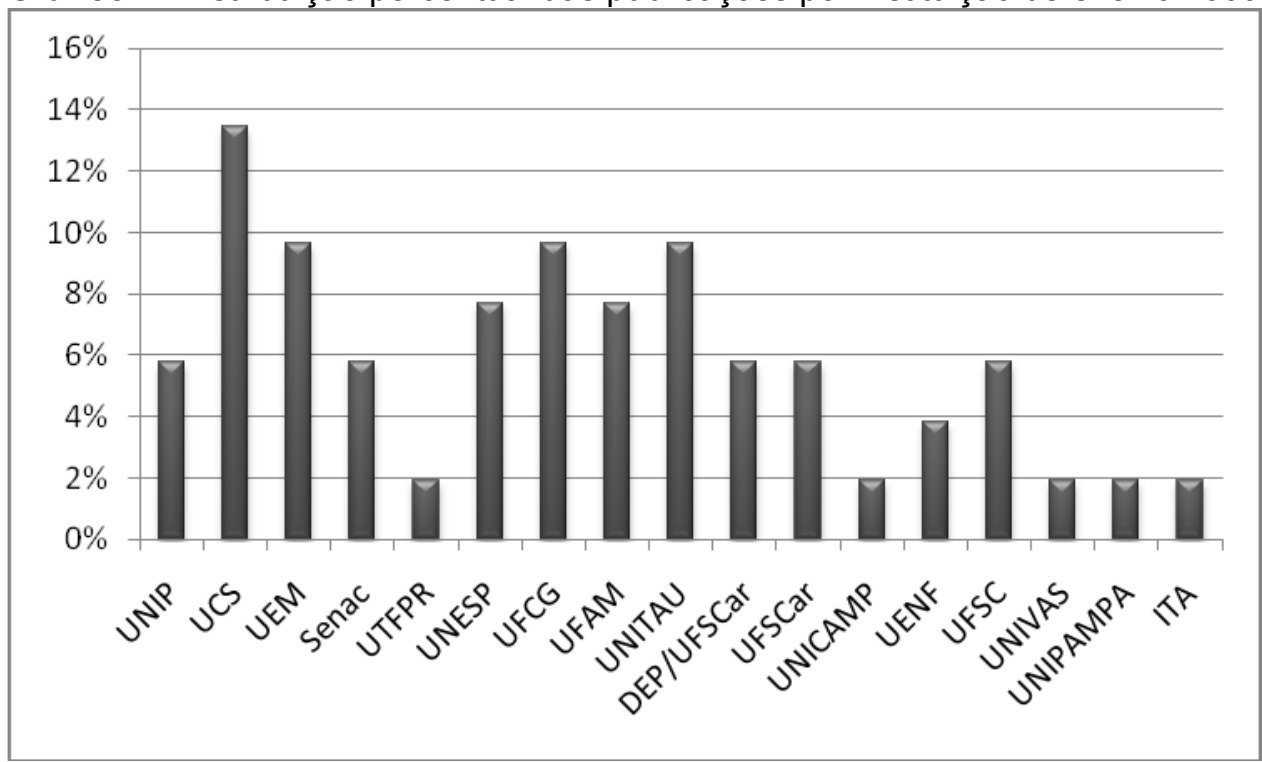

Fonte: Dados Primários (2010)

Com relação à incidência de palavras nos títulos, nota-se que o termo arranjos produtivos locais aparece em 6 artigos e cluster(s) em 2 artigos e nos demais, nenhum dos termos analisados pelo presente estudo foram utilizados, conforme ilustra o Quadro 3.

Quadro 3 - Distribuição de termos nos títulos 2009.

\begin{tabular}{|l|l|}
\hline Palavras no título & Quantidade \\
\hline Arranjos produtivos locais & 6 \\
\hline Cluster(s) & 2 \\
\hline Não contempla os termos pesquisados & 7 \\
\hline
\end{tabular}

Fonte: Dados primários (2010)

Quanto às palavras-chave, Quadro 4, é possível observar que o termo arranjos produtivos locais foi o mais utilizado, já rede(s) de empresas e cluster(s) apareceram somente em um artigo cada uma. Embora se tratasse de 15 artigos, observa-se que quatro artigos não incluíram em suas palavras-chave outros termos correlatos.

Quadro 4 - Distribuição de palavras-chave 2009.

\begin{tabular}{|l|l|}
\hline Palavras-chave & Quantidade \\
\hline Arranjos produtivos locais & 8 \\
\hline Rede(s) de empresas & 1 \\
\hline Cluster(s) & 1 \\
\hline Não contempla os termos pesquisados & 5 \\
\hline
\end{tabular}

Fonte: Dados primários (2010) 
Mediante as análises supracitadas, foram identificados 11 artigos empíricos e 4 artigos teóricos. Destes, 5 estudos foram desenvolvidos no estado de São Paulo, 2 no Rio Grande do Sul e os demais em outras regiões, abordando: fitocosméticos e fitoterápicos; fabricantes de máquinas e equipamentos para a indústria de alimentos e bebidas, indústria aeroespacial e automotivo; vitivinícola; móveis; metalmecânico; confecção e calçados.

A partir da apreciação critica dos resumos pode-se identificar que os principais focos de estudo e/ou objetivo do artigo foram: impulso local que o APL promove; competências inovativas; competências endógenas; desenvolvimento; estrutura organizacional; práticas de gestão da qualidade; rede egocêntrica, cooperação, confiança e poder; características relevantes observadas nos clusters e o adensamento das cadeias produtivas e tecnológicas; mudanças nas características e valores da cultura ambiental em uma rede colaborativa; relações de cooperação entre os agentes; mecanismos de sucesso; saúde no trabalho; metodologia de análise; questões ambientais e indicadores de sustentabilidade na competitividade.

Já no que se refere aos principais resultados verificou-se que: o APL estudado é promissor, mas necessita investimento; falta de foco no futuro; cluster diversificado em termos de ramo de atuação, existência de utilização incipiente e em expansão das práticas de gestão pela qualidade; correlação positiva entre índices de cooperação e confiança, poder concentrado; existência de programas diretos e indiretos de governo que promoveram a formação do cluster, o qual iniciou pela regionalização de empresas multinacionais; o ambiente colaborativo permite que se crie uma cultura ambiental que sustenta valores, hábitos e costumes para toda a sociedade, delineando uma identidade local; melhor estruturação da governança e aprimoramento das relações e dos vínculos de cooperação entre os atores; construção de uma visão compartilhada, coesão estratégica, conscientização acerca da relevância regional do aglomerado; de mercado, ganhos decorrentes da sinergia e uso das competências internas, visão estratégica; modelo de desenvolvimento de APL; baixo nível de competitividade.

Por último, mediante a análise e interpretação global dos dados apresentados, observou-se certa dispersão nos estudos dos artigos, ou seja, assuntos variados tratados dentro da temática relacionada a redes de empresas, tal fato ocorreu 
principalmente nos trabalhos empíricos. Além disso, uma parcela significativa dos estudos não trata a aglomeração como elemento conceitual principal, mas como objeto de estudo. Muitas vezes, o objeto de estudo é a aglomeração produtiva, todavia o foco conceitual de análise não tem convergência com os temas relacionados ao objeto de estudo. Ou seja, numa parcela significativa dos estudos, o foco é a análise de rede de relações quaisquer e não necessariamente arranjos produtivos locais, rede de empresas e clusters.

Percebeu-se ainda, falta de definição clara quanto aos conceitos: arranjos produtivos locais, rede de empresas e clusters. É oportuno destacar também, que o padrão metodológico observado nos artigos dos eventos sugere ampliação no rigor, pois em muitos trabalhos não há definição clara de objetivo, procedimentos metodológicos e principais resultados.

\subsection{Análise do período de 2008}

Em 2008, os temas arranjos produtivos locais, rede de empresas e cluster totalizaram 15 artigos, destes 13 foram publicados no ENEGEP, 1 no ICIEOM e 1 na Revista Produção.

Para os 15 artigos identificaram-se 34 autores, perfazendo uma média aproximada de 2,27 autores por artigo, abrangendo 16 instituições de ensino, o que mais uma vez parece ser um número pouco representativo frente ao universo de instituições de ensino superior no Brasil.

Dentre essas, as instituições com maior percentual de publicação foram: Escola de Engenharia de São Carlos da Universidade de São Paulo - USP, 17\%; o programa de Doutorado em Meio Ambiente e Desenvolvimento da Universidade Federal do Paraná e a Universidade Federal de Santa Maria, com $11 \%$ cada.

O Gráfico 2 apresenta a distribuição percentual das publicações por instituição de ensino. 


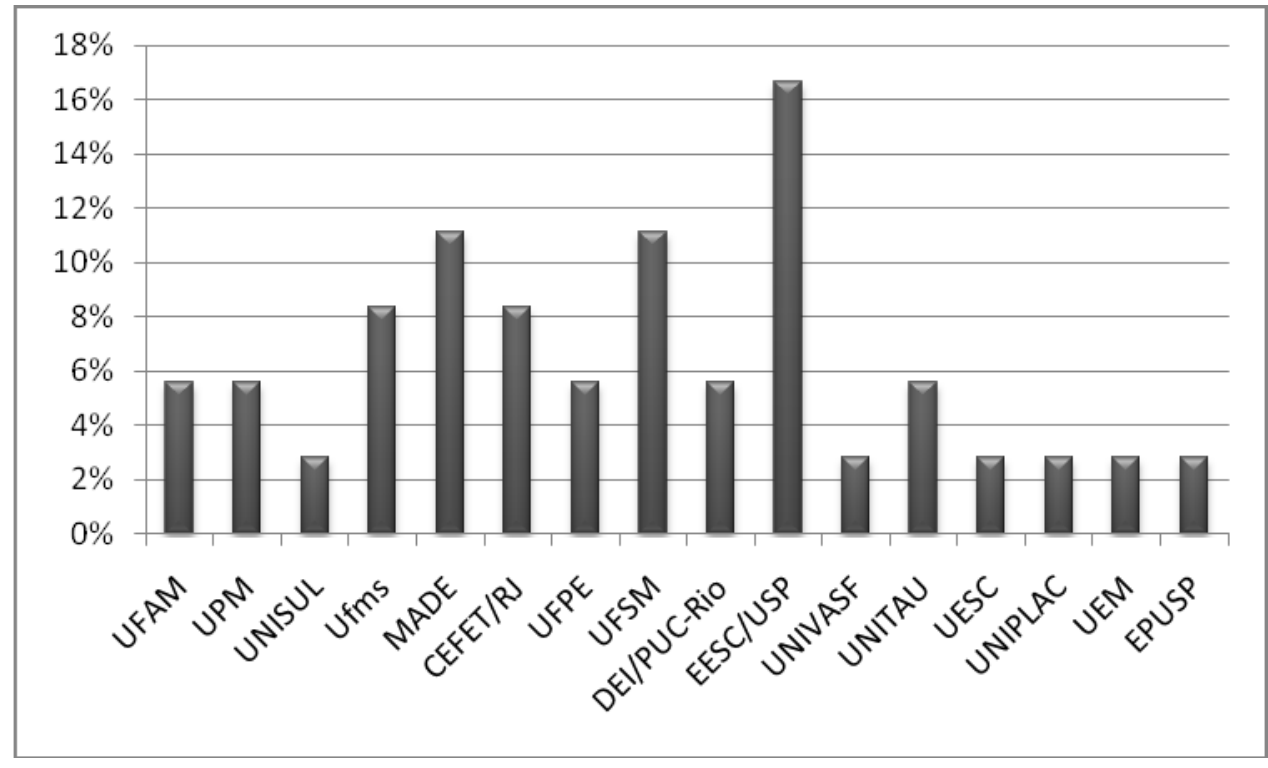

Gráfico 2: Distribuição percentual das publicações por instituição de ensino 2008. Fonte: Dados Primários (2010)

Com relação à incidência de palavras nos títulos, Quadro 5, nota-se que o termo cluster(s) aparece em 4 artigos, rede(s) de empresas em 3 artigos e arranjos produtivos locais em 1 artigo. Os demais não apresentam os termos foco de estudo nos referidos títulos.

Já no que tange às palavras-chave, Quadro 6, observa-se que o termo cluster(s) foi o mais utilizado, seguido de arranjos produtivos locais e, na sequência, redes de empresas. APL, desenvolvimento local e aliança foram citados uma vez cada. No entanto, as demais palavras foco de estudo não foram detectadas.

Quadro 5 - Distribuição de termos nos títulos 2008.

\begin{tabular}{|l|l|}
\hline Palavras no Título & Quantidade \\
\hline Arranjos produtivos locais & 1 \\
\hline Clusters & 4 \\
\hline Redes de Empresas & 3 \\
\hline Não contempla os termos pesquisados & 7 \\
\hline
\end{tabular}

Fonte: Dados primários (2010) 
Quadro 6 - Distribuição de palavras-chave 2008.

\begin{tabular}{|l|l|}
\hline Palavras-chave & Quantidade \\
\hline Arranjos produtivos locais & 4 \\
\hline Clusters & 5 \\
\hline Redes de Empresas & 3 \\
\hline APL & 1 \\
\hline Desenvolvimento local & 1 \\
\hline Aliança & 1 \\
\hline
\end{tabular}

Fonte: Dados primários (2010)

Ainda nas análises referentes ao ano de 2008, foram identificados 12 artigos empíricos e 3 artigos teóricos. Destes, 3 estudos foram desenvolvidos no estado de São Paulo, 2 no Rio Grande do Sul, 1 no Ceará, 1 em Minas Gerais, 3 no Rio de Janeiro e 2 em Santa Catarina e os demais não citavam as regiões envolvidas e/ou são teóricos. Os artigos empíricos, em termos das aglomerações estudadas, tratavam de: bordados, agronegócios de flores e plantas, calçadista, óleo e gás, TIC, moveleiro, têxtil-confecção e cerâmica vermelha.

Quanto ao objetivo dos artigos pode-se destacar: aglomeração geográfica e inovação; criação e desenvolvimento do cluster, perfil dos empresários e papel do governo; sustentabilidade; cooperação e o papel da localidade; sistema de gestão da qualidade; interação entre empresas e instituições de apoio; relacionamentos comerciais; diferenças culturais; evolução sob a ótica dos empresários participantes; relacionamento com fornecedores; articulação; sistemas de informações; características de APL.

A partir dos objetivos acima descritos, os principais resultados gerados pelas publicações, segundo a análise dos resumos, foram: estabilidade da cooperação devido à estrutura de coordenação desenvolvida pela administração da rede; maioria de micro empresas na rede, fatores que favorecem e prejudicam a evolução da rede; a proximidade geográfica favorece a inovação; necessidade de maior integração entre o governo e o arranjo; prática de ações de parceria; estágio atual de desenvolvimento das empresas do cluster e os avanços obtidos nas práticas de gestão e nas operações; preço e qualidade como fatores determinantes da relação com os fornecedores, mas incidência do desenvolvimento da colaboração; necessidade de existência de uma organização representativa do APL e que seja responsável coleta, processamento e disponibilização de informações. Além disso, 
cabe ressaltar que, identificou-se 7 artigos sem menção aos resultados obtidos na pesquisa.

Perante a análise e interpretação global dos dados apresentados, verificou-se que o padrão metodológico observado nos artigos das revistas é de maior rigor que os publicados em anais de eventos. Além disso, nos trabalhos publicados em congressos não se observa uma definição clara de objetivo, procedimentos metodológicos e, principalmente, dos principais resultados da pesquisa. É oportuno ressaltar também, que os trabalhos teóricos são mais focados em tópicos específicos e influentes para estrutura intelectual da referida área de estudo.

\section{CONSIDERAÇÕES FINAIS}

Este trabalho teve por objetivo explorar os artigos relacionados ao assunto aglomerações produtivas nos periódicos da Associação Brasileira de Engenharia de Produção (ABEPRO), nos anais do Encontro Nacional de Engenharia de Produção (ENEGEP) e nos anais do International Conference on Industrial Engineering and Operations Management (ICIEOM). Tal objetivo foi alcançado e demonstrou diversos aspectos relacionados ao estudo das aglomerações produtivas.

Sob aspectos quantitativos, constatou-se um total de 159 artigos relacionados ao tema, com um pico de publicações em 2007, justamente o ano em que uma subárea relacionada a redes e aglomerações foi criada no ENEGEP. Os anos 2008 e 2009 apresentaram queda de interesse no assunto.

Inicialmente, observou-se que nos estudos relacionados ao termo cluster uma parcela significativa dos trabalhos usava cluster como sinônimo de análise de agrupamentos do ponto de vista estatístico, e não de aglomerações produtivas.

Além disso, em 2009 o termo de referência mais utilizado foi APL, já em 2008 foi cluster, mas não demonstrou divergências quanto ao objeto de estudo.

Quanto às instituições que publicaram no referido período, constata-se que não há continuidade nos estudos, bem como não se percebem-se instituições que se destaquem ou sejam referência no estudo do tema. 
Apesar dos tipos de aglomerações produtivas estudadas serem os mais diversos, em relação à concentração geográfica destas, São Paulo possui a maioria dos estudos.

O padrão metodológico observado nos artigos dos periódicos sugere maior rigor metodológico que os publicados nos anais de eventos.

É importante ainda destacar, que se verificou dispersão nos estudos dos artigos, principalmente nos trabalhos empíricos. Falta de definição clara quanto aos conceitos: arranjos produtivos locais, rede de empresas e clusters. E que os estudos não enfatizam aglomeração como elemento conceitual principal, mas sim como objeto de estudo.

Em geral, a análise fornece evidências para a maturação de novas pesquisas de aglomerações produtivas. Pois, se constatou parcialidade nos resultados apresentados nas publicações, e a necessidade de uma abordagem mais assertiva, a qual possa se tornam uma matriz semântica influente para a estrutura intelectual da disciplina.

Cabe ainda ressaltar, que os dados analisados e aqui interpretados são parciais, uma vez que o trabalho limitou-se ao âmbito da ABEPRO e possui nuances qualitativas. Para poder agregar conhecimento potencialmente efetivo à estrutura intelectual de investigação de aglomerações produtivas, é necessário utilizar outros procedimentos metodológicos, como por exemplo, o estudo bibliométrico.

Recomenda-se para novos trabalhos a investigação sobre as causas da diminuição de publicações acontecida em 2008 e 2009. Interessante seria descobrir para que campos do conhecimento da Engenharia de Produção deslocou-se o interesse. Pesquisas em bases internacionais também poderiam contribuir para esclarecer se houve efetivamente perda de interesse e, em caso positivo, se é de caráter nacional ou se está acontecendo também em nível mundial. Uma possível não correlação entre os números nacionais e internacionais poderia indicar necessidades de políticas para incrementar a pesquisa sobre o assunto no país.

Por outro lado, poderia ainda uma investigação mais profunda sobre a constatada diminuição de artigos nos últimos anos sobre o assunto cluster, corroborar ou não os resultados da recente e controversa pesquisa de KUKALIS (2010), da Universidade do Estado da Califórnia, que constatou, com base em 
estudo abrangendo 194 firmas dos segmentos de semicondutores e indústria farmacêutica daquela região "que não há diferenças significativas de performance entre empresas clusterizadas e não clusterizadas"!.

\section{REFERÊNCIAS}

BALESTRIN, Alsones; VERSCHOORE, Jorge. Redes de cooperação empresarial: estratégias de gestão na nova economia. Porto Alegre: Bookman, 2008.

BARROSO, Janayna arruda; SOARES, Alexandre Araújo Cavalcante. O impacto das políticas públicas no desenvolvimento de arranjos produtivos locais: o caso do APL de ovinocaprinocultura em Quixadá, Ceará. Rev. Adm. Pública, Rio de Janeiro, v. 43, n. 6, dez. 2009 . Disponível em:

$<$ http://www.scielo.br/scielo.php?script=sci arttext\&pid=S003476122009000600010\& lng=pt\&nrm=iso

Acesso em: 24 ago. 2010. doi: 10.1590/S0034-76122009000600010.

BOTELHO, Antônio e BASTOS, Glaudson. linnovation as a driver for building an oil \& gas industrial cluster in Rio de Janeiro, Brazil. In: From agglomeration to innovation upgrading industrial clusters in emerging economies, London, MacMillan, 2011.

CASAROTTO FILHO, Nelson; PIRES, Luis Henrique. Redes de pequenas e médias empresas e desenvolvimento local: estratégias para a conquista da competitividade global com base na experiência italiana. São Paulo: Atlas, 2001.

CASTELLS, Manuel. A Sociedade em rede. 4. ed. Rio de Janeiro: Paz e Terra, 2000.

CROCCO et al. Metodologia de Identificação de arranjos produtivos locais Potenciais. Texto para Discussão no 212. Julho de 2003. Disponível em:

<http://www.cedeplar.ufmg.br/pesquisas/td/TD\%20212.pdf>. Acesso em: jan. 2009.

DING, Ke The role of the specialized markets in upgrading industrial Clusters in China. In: From agglomeration to innovation upgrading industrial clusters in emerging economies, London, MacMillan, 2011.

GIL, Antonio Carlos. Métodos e técnicas de pesquisa social. 5. ed. São Paulo: Atlas, 1999.

GIL, Antonio Carlos. Como elaborar projetos de pesquisa. São Paulo: Atlas, 2002.

KUKALIS, Sal. Agglomeration economies and firm performance: the case of industry clusters. Journal of Management California, v.36, 2010. 
LEON, F. e MEIRELLES, D. Vantagens da aglomeração de serviços: um ensaio teórico. SIMPOI 2010. Disponível em:

<http://www.simpoi.fgvsp.br/arquivo/2010/artigos/E2010 T00347 PCN67608.pdf>.

Acesso em: 16 out. 2010.

LIAO, Tsai-Ju. Cluster and performance in foreign firms: the role of resources, knowledge, and trust. Industrial Marketing Management. Disponível em:

$<$ http://www.sciencedirect.com/science/article/B6V69-4TKNJD3-

1/2/6c632d10ab956d6fe08a0353576b744b>.

Acesso em: 15 set. 2010.

McCANN, Brian; FOLTA, Timothi .B. Location Matters: Where We Have Been and Where We Might Go in Agglomeration Research. Journal of Management, v. 34, n. 3, p.532-565, 2008.

PORTER,M.L. Clusters and the new economics competition. Harvard Business Review. V.76, n. 6, nov./dez.1998.

RAUEN, F. J. Roteiros de investigação científica. Tubarão: Unisul, 2002

ROESCH, S. A. Projetos de estágio e de pesquisa em administração. 2. ed. São Paulo: Atlas, 1999.

SERVIÇO BRASILEIRO DE APOIO ÀS MICRO E PEQUENAS EMPRESAS . Termo de referência para atuação do sistema SEBRAE em arranjos produtivos locais, 2003. Disponível em: <http://www.busca.sebrae.com.br/search?>. Acesso em: 25 ago. 2010.

THIOLLENT, Michel. Crítica metodológica, investigação social e enquete operária. São Paulo: Polis, 1980.

VILPOUX, Olivier F.; OLIVEIRA, Eule José de. Instituições informais e governanças em arranjos produtivos locais. Rev. Econ. Contemp., Rio de Janeiro, v. 14, n. 1, 2010. Disponível em:

<http://www.scielo.br/scielo.php?script=sci arttext\&pid=S1415-

98482010000100005\&lng=pt\&nrm=iso>. Acesso em: 24 ago. 2010. doi:

10.1590/S1415-98482010000100005

ZACCARELLI, Sergio B. et al. Clusters e redes de negócios: uma visão para a gestão dos negócios. São Paulo: Atlas, 2008.

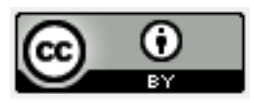

Artigo recebido em 13/05/2011 e aceito para publicação em 17/08/2011. 